\title{
La muerte como oportunidad para renunciar a la herencia
}

\section{Death as oportunity to give up heritage}

\author{
Gladis Milagros Valencia Hernandez
}

\begin{abstract}
RESUMEN
El fin de la persona humana es la muerte, si bien es doloroso para la familia del fallecido su deceso, resulta ser -en algunos casos- todo un embrollo el inicio de procedimientos para regularizar la situación jurídica del causante y la de sus herederos.En esta sección se analiza que está sucediendo ante la falta de indicación expresa en el art. 673 del Código Civil sobre el plazo para renunciar a la herencia; evaluando las diversas posturas de nuestros juristas, comparándolo con otras legislaciones. También se analiza doctrinariamente el contenido del art. 33 del Reglamento de Inscripciones del Registro de Sucesiones Intestadas y Testamentos, así como también se interpreta el contenido del art. $673^{\circ}$ del Código Civil en concordancia con las posturas doctrinarias, registrales y ordenamientos jurídicos extranjeros.
\end{abstract}

Palabras clave: Renuncia; Vocación hereditaria; causante; heredero.

\section{ABSTRACT}

The end of the human person is death, although it is painful for the family of the deceased his death, it turns out to be - in some cases - a whole mess the beginning of procedures to regularize the legal situation of the deceased and that of his heirs. This section analyzes what is happening in the absence of express indication in art. 673 of the Civil Code on the term to renounce the inheritance; evaluating the various positions of our jurists, comparing it with other laws. The content of art is also doctrinally analyzed. 33 of the Registration Regulations of the Registry of Intestate Successions and Wills, as well as the content of art. $673^{\circ}$ of the Civil Code in accordance with foreign doctrinal, registration and legal positions.

Keywords: Waiver; Hereditary vocation; cause; inheritor.

\section{Análisis del plazo para renunciar a la herencia.}

Durante algunos años, gracias a la experiencia laboral adquirida en la Superintendencia Nacional de los Registros Públicos -en virtud a la pre calificación registral de los títulos- se advirtió la problemática que hoy resalto: en el art. 673 del Código Civil no se señala desde cuando se computa el plazo para renunciar a la herencia; sin embargo, el Tribunal Registral en jurisprudencia reiterada ha considerado que se debe computar dicho plazo desde la fecha de la inscripción de la sucesión.

Ahora, si de acuerdo al art. 660 del Código Civil los bienes derechos y obligaciones que constituyen la herencia se transmiten a los herederos desde la muerte del causante, ¿por qué considerar que el plazo para la renuncia se computará desde la inscripción de la sucesión, si es a partir de la muerte del causante que se apertura y se efectúa el llamado a los posibles herederos?

Por su parte, la interpretación que realiza el Tribunal Registral respecto al plazo para la renuncia de la herencia hace una distinción, según nos encontremos ante una sucesión intestada o testamento. A saber: En la Resolución N²54-2017-SUNARP-TR-A y N³55-2013SUNARP-TR-A, el Tribunal Registral considera que, en caso de testamentos, el plazo para renunciar a la herencia debe ser computado desde la apertura de la sucesión, es decir, a partir de la fecha del fallecimiento del causante; mientras que en la Resolución $N^{\circ} 1065-$ 2016-SUNARP-TR-L se señala expresamente que los plazos previstos en el art. 673 del Código Civil se computan a partir de la fecha de la inscripción de la declaratoria de herederos o de la ampliación de testamento, según sea el caso.

Por otro lado, el art. 33 del Reglamento de Inscripciones del Registro de Testamentos y de Sucesiones Intestadas, aprobado por Resolución N0156-2012-SUNARP, señala lo siguiente: "El título para la inscripción de la renuncia a la herencia es el parte notarial de la escritura pública. Para la inscripción de la renuncia de herencia se requiere la previa inscripción de la sucesión intestada".

Así, de dicho precepto normativo podemos advertir que, para la Superintendencia Nacional de los Registros Públicos, es presupuesto para renunciar a la herencia que previamente se encuentre inscrita la sucesión intestada, extendiendo así el plazo para renunciar a la herencia, condicionando al renunciante a iniciar el procedimiento de sucesión intestada para que pueda declinar a la herencia, lo que resulta contradictorio con lo establecido en el Código Civil.

En nuestra doctrina también existe esta disparidad. Por ejemplo, el maestro Lohmann (1995) considera que "el plazo para renunciar a la herencia debe computarse desde la fecha en que el llamado esté en aptitud de saber del llamamiento" (p. 236); esto es, la fecha de la inscripción de la sucesión intestada o la fecha de la inscripción de la ampliación de testamento. Posición distinta es la de Ferrero (2016), quien considera que el plazo se debe computar desde la apertura de la sucesión, es decir, al fallecimiento del causante, a pesar que el código no lo dice. Así mismo señala: La Comisión Revisora expresó que estos plazos se contaban desde la presentación del inventario en el caso del heredero que quería suceder intra vires hereditatis, y desde la muerte del causante en los demás. Al no haberse tomado en cuenta la obligación de inventariar en el Código, debe aceptarse que en cualquier caso los plazos se computan desde la muerte (p.245)

Ahora, estas posturas dispares generadas por la falta de señalamiento expreso respecto al momento desde el cual se computará el plazo para renunciar a la herencia, genera incertidumbre en los llamados a recibir la herencia, quienes no saben desde qué momento pueden ejercer tal derecho. Así, si bien la aceptación presunta de 
la herencia (transcurrido el plazo señalado en el art. $673^{\circ}$ del Código Civil sin renunciar) podría no ser gravosa, esto dependerá de si el causante ha dejado dentro de la herencia una gran cantidad de deudas, las cuales quizá son mucho más que los bienes que se transmitirán por la apertura de la sucesión. Por lo que si las cargas y obligaciones del causante superan los bienes que ha dejado, puede ocurrir que al aceptar la herencia, el heredero suceda un todo que se integrará al patrimonio de éste, debiendo también afrontar sus pasivos, que aún cuando no le correspondían, ya pasaron a ser suyas por su aceptación a la herencia.

Incluso, a primera vista, el art. $661^{\circ}$ del Código Civil nos lleva a entender que el heredero no responde con su patrimonio ante las deudas del causante, pero ello no es del todo cierto, pues dependerá de si al aceptar la herencia de manera expresa se realizó o no un inventario, o que no habiéndolo hecho pueda probarse después la insuficiencia de la masa hereditaria.

Lohmann (1995) refiere: "Sostener la tesis contraria (...) conduciría, sin duda, a varias incongruencias (...) b) La segunda incongruencia de la tesis contraria radicaría en la inutilidad de las normas de aceptación y repudiación de la herencia, porque si estas son instituciones diseñadas para que el sucesor decida si quiere tomar o no las posiciones jurídicas del causante, incluyendo los pasivos, perderían toda razón de ser si por una supuesta responsabilidad limitada impuesta legalmente, el heredero nunca toma más pasivos de las que puedan ser cubiertas con los activos" (p. 70).

Entonces, como no se tiene certeza si se renuncia al llamamiento o al título de heredero, ni desde cuando opera el plazo para renunciar a la herencia, podría ocurrir que quien en verdad desee renunciar ya no lo pueda hacer, debido que el juez, notario o funcionario de Sunarp -ante quien se expresa la voluntad de negaciónpuede considerar desde su perspectiva que ya transcurrió el plazo señalado en el art. $673^{\circ}$ de la norma sustantiva, y por tanto que se ha configurado la aceptación presunta, la misma que -de contener la herencia mas pasivos que activos- perjudicará al heredero si es que no puede probar el exceso de pasivo en la herencia, y más aún si existen acreedores del causante que requieran el cobro de su deuda. Es decir, que la norma no determine el momento desde el cual una persona puede renunciar a la herencia, deja a discreción del notario, juez, abogados y otros, la interpretación o sentido que se le quiera otorgar, y ello podría perjudicar al posible llamado que no desea suceder.

En el Derecho Comparado, por el contrario, existe mayor claridad respecto al plazo para renunciar, toda vez que se señala de manera expresa desde cuándo se puede renunciar. Por ejemplo, en el Código Civil Chileno, cuando se refiere a la sucesión, ya sea testada o intestada, utiliza el término asignación, llamando al posible heredero como asignatario, y éste puede repudiar la asignación desde la muerte del causante, incluso lo puede hacer en cualquier momento mientras tenga derecho; asimismo, la ley presume que el heredero repudia la herencia cuando este se constituye en mora de declarar si acepta o no, así, específicamente en su art. 1233 se señala que se entiende que el heredero repudia, cuando se constituye en mora de declarar si acepta o repudia. En Argentina, similar a lo que ocurre en Chile, tenemos que el plazo para renunciar a la herencia está debidamente determinado, incluso se indica desde cuando se computará dicho plazo: desde la apertura de la sucesión, esto es, desde la muerte del causante.
En tal sentido, conforme lo hemos expuesto, se puede colegir que al no fijarse en la norma (art. 673 del Código Civil) la fecha del inicio del cómputo del plazo para renunciar a la herencia, ello ocasiona una diversidad de interpretaciones tanto para los juristas como para los tribunales peruanos.

Ahora, existe un artículo redactado por el abogado Saavedra(2014) y publicado en la revista IUS ET VERITAS, en la cual expone su posición respecto a la omisión de señalar el computo del plazo para renunciar a la herencia, comparando y criticando la actual redacción del art. 673 del Código Civil con el texto propuesto en el Proyecto de Ley 582/2011-CR que reforma varios artículos del mencionado código:

Como adecuadamente es indicado en la propuesta de reforma, el inconveniente radica en que en la actualidad no se fija la fecha de inicio del cómputo de plazo. En este punto me parece adecuado establecer en el numeral primero la fecha de apertura del testamento o la fecha en que la declaratoria de herederos se torna firme como el momento de inicio del término dentro del cual deberá emitirse la aceptación expresa (o entrará a tallar la aceptación presunta); sin embargo, deseo expresar mi disconformidad con el texto propuesto en otros extremos (Saavedra, 2014, p. 208).

Asimismo, tenemos que por Ley N. 26394 publicada el 22 de noviembre de 1994, modificada por Ley N. 26673, el Congreso de la República conformó una comisión para elaborar el anteproyecto de ley de reforma del Código Civil. Es así que, mediante Oficio N. 916-2010-2011-CJ$\mathrm{DDHH} / \mathrm{CR}$ el Presidente de la Comisión de Justicia y Derechos Humanos remitió al Congreso de la República el Informe Final aprobado por la Comisión Especial de Estudio del Anteproyecto de la Ley de Reforma del Código Civil, en el cual consta la modificatoria planteada sobre el art. 673 -entre otros artículos-, y se propone que su redacción sea la siguiente:

\section{"Art. 673.- Plazo de aceptación o renuncia.}

1. Si el llamado a la sucesión como heredero no la aceptara ni renunciara dentro de los noventa días de conocido por él el contenido del testamento o, en su caso, de haber adquirido firmeza la declaración de sucesión legal y llamamiento de herederos, los demás llamados a la sucesión, los acreedores de aquellos y de ésta, pueden requerirlo notarialmente para que dentro de un plazo no mayor de noventa días desde notificado el requerimiento, declare si acepta la herencia o la renuncia. Si se desconociera el domicilio, el requerimiento será judicial y por edictos, tramitándose como proceso no contencioso.

2. A falta de declaración de aceptación expresa, o de que el requerido haya supeditado su aceptación al resultado del inventario de la masa, o de renuncia dentro del plazo señalado en el inciso 1, la herencia se tiene por aceptada pura y simplemente, salvo que el llamado fuera una persona incursa en los artículos 43 ó 44 o una repartición estatal."

Por otro lado, la Comisión de Justicia y Derechos Humanos del Congreso de la República aprobó en el año 2014, el dictamen respecto al Proyecto de Ley $N^{\circ} 582 / 2011-C R$ en el que se proponía la modificación de diversos artículos de nuestra norma sustantiva, entre los cuales está nuevamente en propuesta el art. 673:

\section{"Artículo 673.- Plazo de aceptación o renuncia}

1. Si el llamado a la sucesión como heredero no la acepta ni renuncia dentro de los noventa días de conocido el contenido del testamento 0 , en su caso, de haber 
adquirido firmeza la declaración de sucesión legal y llamamiento de herederos, los demás llamados a la sucesión, los acreedores de aquellos y de ésta, pueden requerirlo notarialmente para que dentro de un plazo no mayor de noventa días desde (sic) notificado el requerimiento, declare si acepta la herencia o la renuncia (sic). Si se desconoce el domicilio, el requerimiento será judicial y por edictos, tramitándose como proceso no contencioso.

2. A falta de aceptación expresa, o que el requerido haya supeditado su aceptación al resultado del inventario de la masa, o de renuncia dentro del plazo señalado en el inciso 1, la herencia se tiene por aceptada pura y simple, salvo que el llamado fuera una persona incursa en los artículos 43 o 44 o una repartición estatal.

\section{Estos plazos no se interrumpen por ninguna causa."}

Tenemos también el Proyecto de Ley N499/2016-CR presentado ante el Congreso el 28 de octubre del 2016 por el Grupo Parlamentario Peruanos por el Cambio.

Dicho proyecto es referente a la modificación de diversos artículos del Código Civil, entre ellos el art. 673, siendo la modificatoria propuesta la siguiente:

\section{"Art. 673. Plazo de aceptación o renuncia a la herencia}

1. Si el llamado a la sucesión como heredero no acepta ni renuncia a la herencia dentro de los noventa días de la apertura o de la protocolización del testamento o, en su caso, de haber adquirido firmeza la declaración de sucesión legal y llamamiento de herederos, los demás llamados a la sucesión, los acreedores de aquellos y de esta pueden requerirlo notarialmente para que dentro de un plazo de noventa días desde notificado el requerimiento, se declare si acepta la herencia o renuncia a ella. Si se desconoce el domicilio, el requerimiento será judicial y por edictos, tramitándose como proceso no contencioso.

2. A falta de aceptación expresa, o habiendo el requerido supeditado a su aceptación al resultado del inventario de la masa hereditaria, o no habiendo renuncia dentro del plazo señalado en el inciso 1, la herencia se tiene por aceptada pura y simple, salvo que el llamado a la sucesión como heredero fuese una persona incursa en los artículos 43 ó 44 o una repartición estatal.

\section{Estos plazos son de caducidad.}

4. Estas disposiciones son aplicables al legado en lo pertinente.

Si bien estas propuestas legislativas pretenden señalar expresamente como computar el plazo para la aceptación o renuncia de la herencia, consideramos que ello no es acorde con la postura del propio código respecto a la transmisión de la herencia y lo establecido en el art. 660 de la norma sustantiva.

\section{Lohmann (2015) manifiesta:}

El tema de la presunción de la aceptación de la herencia siempre ha sido un asunto muy elemental, y lo que el Proyecto incluía en su tratamiento era una serie de supuestos que estimamos no vienen al caso, pues se estaría reglamentando en exceso y hasta burocratizando el asunto. (p. 14-15).

El art. $673^{\circ}$ del Código Civil debe ser analizado e interpretado teniendo en cuenta también el art. $660^{\circ}$ del mismo cuerpo legal.

Así, a la muerte del causante, la transmisión de la sucesión opera automáticamente; entonces, debemos entender que es a partir de este momento que el heredero puede renunciar a la herencia, pues en dicha oportunidad se configura lo que se denomina en la doctrina como la apertura de la sucesión.

Ahora, si consideramos -como lo hace Lohmann que para renunciar a la herencia, previamente el llamado a heredar debe conocer sobre la existencia de ella, que se configuraría cuando se inscribe la sucesión intestada en el Registro correspondiente, a tenor del Principio de Publicidad contenido en el art. 2012 del código sustantivo, o tomando en cuenta el acta notarial o resolución judicial de sucesión intestada; ello genera incertidumbre y condiciona al llamado a heredar a esperar que se realice un procedimiento previo (proceso judicial o notarial de sucesión intestada, con su debida inscripción registral, de acuerdo a lo regulado en el art. 33 del Reglamento de Inscripciones del Registro de Sucesiones Intestadas y Testamentos) para que recién pueda renunciar a aquello que no desea tener, obligándolo a un gasto innecesario cuando no desea -finalmente-ser reconocido como heredero.

Incluso, si fuera una sola persona la llamada a heredar, se le está condicionando que previamente a su renuncia, inicie el proceso notarial o judicial de sucesión intestada, lo que ocasiona un trámite innecesario y una inscripción que, al fin de cuentas, no surtirá efectos.

Ahora, aún cuando las propuestas legislativas detalladas anteriormente, pretenden señalar expresamente desde cuando computar el plazo para la aceptación o renuncia de la herencia, consideramos que ello no es acorde con la postura del propio código respecto a la transmisión de la herencia y lo establecido en el art. 660 de la norma sustantiva.

Por tanto, la norma no señala desde cuándo se debe computar el plazo para renunciar a la herencia, sin embargo, haciendo una interpretación sistemática de normas, podemos concluir que el plazo para renunciar debe computarse desde la muerte del causante.

No se puede condicionar al posible heredero a que, previamente a su renuncia, se inscriba su derecho en el Registro pertinente, cuando es con la apertura de la sucesión que se configura la transmisión de la herencia.

El art. 33 del Reglamento de Inscripciones del Registro de Sucesiones Intestadas y Testamentos condiciona al posible heredero a inscribir su derecho, previo a efectuar su renuncia, lo que traslada una carga innecesaria en aquel, quien finalmente no quiere la herencia ni se beneficiará con la misma.

Si para renunciar a la herencia se computa el plazo desde su inscripción registral, en virtud a la seguridad jurídica y a la publicidad que brinda el Registro (SUNARP), podemos suponer que la misma seguridad la brinda la inscripción de la fecha del fallecimiento en el Registro Civil del RENIEC, por lo que para quien desee renunciar a la herencia le resulta más sencillo obtener tal información de esta institución, que tramitar la sucesión intestada para recién poder repudiar la herencia.

Se propone mediante la presente investigación una modificatoria parcial del art. 673, en el sentido que se deberá considerar lo siguiente: Los posibles llamados a heredar pueden renunciar a la herencia desde la muerte del causante y hasta antes de cumplido el plazo para aplicar la presunción de la aceptación: Esto de acuerdo a lo establecido en el art. $660^{\circ}$ del Código Civil. Esta propuesta es recogida por la legislación argentina y por la chilena; y si bien en ellas se consigna como plazo uno mayor (mucho mayor diríamos), ambas coinciden en considerar que la renuncia a la herencia es factible desde 
la fecha de fallecimiento del causante porque en dicho momento es cuando se apertura la sucesión.

Incluso, consideramos prudente que se deje sin efecto el último párrafo del art. $33^{\circ}$ del Reglamento de Inscripciones del Registro de Sucesiones Intestadas y Testamentos; ya que dicho precepto ampliaría el plazo para renunciar a la herencia; generando un presupuesto previo que la norma de superior jerarquía no regula, desnaturalizando de esa manera la institución de la renuncia hereditaria, pues estaría condicionando a quien no quiere la herencia a declarársele heredero primero, lo cual resulta contradictorio.

\section{REFERENCIAS BIBLIOGRÁFICAS}

Decreto Legislativo N²95, (2014). codigo Civil, libro IV. Derecho de suseciones. Ministerio de Justicia y Derechos Humanos.Lima

Ferrero, A. (2016). Tratado de Derecho de Sucesiones. Lima, Perú: Instituto Pacífico.
Lohmann, G. (1995). Derecho de Sucesiones, Sucesión en General. Lima, Perú: Fondo Editorial de la PUCP.

Lohmann, G. (2015). Gaceta Civil y Procesal Civil. Tomo, (19), p. 14-15.

Resolución N 156 - 2012 - SUNARP - gr (2012). Reglamento de inscripción de los Registros de testamentos y de sucesiones intestadas. Superintendencia Nacional de Registros Públicos. Lima

Saavedra, Renzo (2014). Cambiar para mejorar...no para confundir: Comentarios críticos sobre la reforma al libro de Sucesiones. Ius et Veritas. Volumen (49), p. 208-221. 